\title{
The reduction of chemical control of leek rust, a simulation study
}

\author{
P. D. de Jong ${ }^{1}$, R. A. Daamen ${ }^{1}$ and R. Rabbinge ${ }^{2}$ \\ ${ }^{1}$ Research Institute for Plant Protection, P.O. Box 9060, NL-6700 GW Wageningen, The Netherlands (Fax: 08370 \\ - 10113); ${ }^{2}$ Wageningen Agricultural University, Department of Theoretical Production Ecology, P.O. Box 8025, \\ 6700AK Wageningen, The Netherlands
}

Accepted 13 April 1995

Key words: epidemiology, supervised control, leek rust, prevention, simulation

\begin{abstract}
A model is presented which simulates chemical control against leek rust under a system of supervised control. The spread of disease between fields in one farm and the influx of spores from outside is part of the model. The possible reduction in fungicide sprays against leek rust following various preventive measures is estimated with this model. Results from this preliminary model suggest that supervised control of leek rust will result only in a considerable reduction in the number of fungicide sprays if the leek fields are sufficiently isolated and the planting material is initially disease free. Where isolation between the fields is not feasible, overlap between successive crops should be avoided. Without the use of these preventive measures, there is little prospect for supervised control and the grower will have no option but the heavy use of fungicides.
\end{abstract}

\section{Introduction}

The pathogen causing leek rust, Puccinia allii Rudolphi, needs to infect new crops of leek (Allium porrum L.) before the harvest of infected crops to ensure its survival. Resting spores and alternative hosts are of minor significance in the pathogen's epidemiology. Only the uredosori are commonly present in the Netherlands; teleutosori are rarely observed [de Jong, 1994]. Rust of leek can infect $A$. vineale L. [Jennings et al., 1990a] which is a common wild plant in the Netherlands but isolates are not infective on leek [R. Niks, pers. comm.] and are described as a different rust species, $P$. mixta Fuckel [Niks and Butler, 1993]. Leek cultivation is continuous over the year in the Netherlands, with ample overlap between the crops. The early summer crops are planted in April and harvested in July. The late winter crops are planted in July and harvested during winter and spring until May the following year. The disease is able to survive low temperatures during winter in infected plants, permitting regrowth once temperatures rise. At present, there are no completely resistant leek cultivars, but differences in susceptibility have been found among cultivars in the United Kingdom [Uma and Taylor, 1991; Smith and Crowther, 1992], Germany [Albert and Smolka, 1994] and the Netherlands [de Jong, 1994].

Research on the control of leek rust has concentrated on breeding for resistance [Jennings et al., 1990a; Uma and Taylor, 1991; Smith and Crowther, 1992] and the optimal use of fungicides [von Meyer and Kessler, 1990; de Jong, 1995], but little attention has been given to preventive measures. This study focuses on the opportunities for and benefits of preventive measures for individual growers, to reduce the need for chemical control against leek rust; these can be divided into strategic measures and tactical measures [Conway, 1984]. Strategic measures are: 1. reduction of influx of spores from outside the farm by moving to a less dense production region, 2 . increase of the isolation between fields within the farm to reduce spread of spores between fields, 3 . change to a cropping pattern with less overlap between successive crops. Tactical measures are: 1. use of less susceptible cultivars (hypothetical) or cropping practices that reduce the disease increase, 2. inspection of planting material and refusal of infected planting material. To obtain information on the effect of the three strategic measures, research at 
the cropping system level is necessary, but is expensive due to the large experiments required. A survey of leek farmers is a less costly alternative for experimental research, but observations must cover several years. Before starting expensive experimental research or a lengthy survey, the possible effect of preventive measures can be explored with simulation modelling. In this paper, a simulation model is used to estimate the possible reduction in fungicide sprays against leek rust due to preventive measures.

\section{Materials and methods}

\section{Model}

Consider a leek grower having four leek fields, one is planted with a winter crop, to be harvested in April or May, another planted with an early summer crop in April and harvested in July or August, a third field planted with an autumn crop in June and harvested in November and the last field planted in July or August with next year's late winter crop, and harvested in April or May next year. This cycle is repeated every year. The grower has adopted the following system of supervised control of leek rust, and monitors crops weekly and applies fungicide to a crop every fortnight, as soon as disease is detected in the crop, i.e. when the mean number of uredosori per plant is one. With an appropriate sampling method, this is practically feasible [de Jong, 1995]. The fungicide does not affect the uredosori already present, but it protects the crop against new infections. No fungicide is applied in a period of 14 days before harvest.

The mean number of uredosori per plant in a field increases from autoinfection, due to alloinfection from other infected fields on the same farm and due to influx of spores from outside the farm. The number of infections initiated by autoinfection during one day is assumed to be proportional to the number of uredosori present in the field, thus assuming exponential growth in the absence of alloinfection [de Jong, 1994]. The number of infections initiated in a field due to alloinfection from another field on the same farm is assumed to be proportional to the number of infections initiated by autoinfection in the source field during the same day. It is assumed that there is a constant influx of spores from outside the farm.

The latent period (from infection to uredosori) was assumed to be constant for all infections ( $p$ days). The number of uredosori occurring during day $t$ in field $i$ due to autoinfection is assumed to be proportional to the number of uredosori present in that field $p$ days before. The corresponding proportionality factor is the relative multiplication factor $R$. The number of uredosori occurring during day $t$ in field $i$ due to alloinfection from field $j$ is proportional with a factor $c_{i j} R$ to the number of uredosori present in field $j p$ days before. The mean number of uredosori per plant in a field, $X(t)_{i}$, is initialized by equating to $X_{0}$, i.e. the disease level in the planting material, for the period starting from planting till $p$ days after planting. As a result of the above assumptions, the increase in mean number of uredosori per plant in a field, $p$ or more days after planting, is described by the following relation:

$$
\begin{gathered}
X(t+1)_{i}=X(t)_{i}+\left(R * X(t-p)_{i}+\right. \\
\left.\sum_{j=1, j \neq i}^{n} c_{i j} * R * X(t-p)_{j}+f\right) * s(t-p)_{i}
\end{gathered}
$$

with the following variable (dimensions are given in []):

$X(t)_{i}$, mean number of uredosori per plant in field $i$ at day $t$ [pustule.plant ${ }^{-1}$ ],

and the following parameters:

$R$, daily relative multiplication factor for autoinfection $\left[\right.$ day $\left.^{-1}\right]$,

$p$, duration of the latent period [day],

$n$, the number of fields contributing to alloinfection $[-]$,

$c_{i j}$, proportionality factor for alloinfection of field $i$ from a neighbour field $j[-]$,

$f$, constant daily number of uredosori due to influx of spores from outside the farm [pustules. plant $^{-1}$.day $\left.{ }^{-1}\right]$,

$s(t)_{i}$, the factor accounting for the effect of a protecting fungicide in field $i$ on day $t[-]$.

\section{Parameters}

The period of the year favourable for increase of leek rust is assumed to be between 1 April and 1 November when the latent period is assumed to be constant and 14 days long [Jennings et al., 1990a, b; Uma and Taylor, 1991, de Jong, 1994]. The relative growth rate of the disease $r$ was found to be variable with the growth stage of the crop [de Jong, 1994]. As a simplification, $r$ is assumed to be constant at a value of 0.12 day $^{-1}$ for a highly susceptible cultivar [de Jong, 1994]. To simulate partial resistance or cropping practices that restrain the disease increase, a relative growth rate of 0.06 day $^{-1}$ was assumed, without changing the length 
of the latent period. The daily relative multiplication factor $R$ used in (1) is calculated from the relative growth rate $r$ in the absence of alloinfection, and the latent period $p$ with the following equation:

$$
R=\left(e^{r}-1\right) * e^{r p}
$$

[de Jong, 1994].

From 1 November to 1 April, weather conditions were assumed to be unfavourable for new infections and $\mathrm{r}=0$. During this period, the mean number of uredosori per plant is assumed to be halved due to weathering of the leek plants. This is a conservative estimate based on observed reductions (Table 1). The parameters $c_{i j}$ are measures for spore transport between fields and their values will be lower with better isolation between fields. It is convenient to restrict the analysis where $c_{i j}$ is independent of the two particular fields, i.e. assume $c_{i j}=c$ for all $i, j$. For an estimate of how $c$ may be related to the distance between the fields and the size of the fields, all individual plants in the source field can be considered as point sources. We use an exponential model [Kiyosawa and Shiyomi, 1972] to describe the infection gradient from these point sources and assume a homogeneous spatial distribution of the disease. The average number of infections $c$ received per plant in the recipient field as a result of spores originating from all plants in the source field can be calculated as:

$$
c=\frac{1}{N} \sum_{k=1}^{N} \sum_{l=1}^{N} a e^{-b d_{k l}}
$$

in which $d_{k l}$ is the distance in meters between plant $k$ in the recipient field and plant $l$ in the source field, $N$ is the number of plants in each equal sized field, $a$ is a scaling parameter and $b$ is a parameter determining the steepness of the infection gradient. Estimates for $b$ for uredospores of leek rust are not available. For uredospores of $P$. graminis Pers. and $P$. recondita Rob. \& Desm. estimates for $b$ range from 0.02 to 1.4 $\mathrm{m}^{-1}$ [Aylor, 1987; Fitt, Gregory, Todd, McCartney and Macdonald, 1987], the first value representing the shallowest gradient and dispersal over the longest distance. By fitting a model very similar to model (1) to the results of a previous experiment with leek rust, $c$ was estimated to be between 0.02 and 0.04 for adjacent plots measuring $12.5 \mathrm{~m} \times 8 \mathrm{~m}$ and with a planting distance of $0.5 \mathrm{~m} \times 0.2 \mathrm{~m}$ between and in the row [de Jong, 1994a]. With these geometrical characteristics and $c=0.04$ and $b=0.02$ (representing maximal
Table 1. Observed reduction in mean number of uredosori per plant in fields planted with hardy cultivar Carina (planted begin of July) during two winters (sample size was 90 plants, values with the same letter within one season are not significantly different at $\alpha=0.05$ according to LSD-test)

\begin{tabular}{lcl}
\hline Date & $\begin{array}{l}\text { Mean number of } \\
\text { uredosori per plant }\end{array}$ & $\begin{array}{l}\text { Reduction } \\
(\%)\end{array}$ \\
\hline 17 Dec 1991 & $58.1 \mathrm{a}$ & 41.5 \\
26 Feb 1992 & $\begin{array}{l}34.0 \mathrm{a} \\
\text { 30 Nov 1992 }\end{array}$ & $\begin{array}{l}122.0 \mathrm{a} \\
\text { 3.0 } \mathrm{b}\end{array}$ \\
\hline
\end{tabular}

spore dispersal), a value of $4.9 * 10^{-5}$ was obtained for $a$ by heuristically applying (3). With (3), the decline of $c$ with increasing distance between borders of fields was calculated. As $c$ is inversely proportional to the isolation between fields, $-\log (c)$ can be considered as a measure of isolation between fields and is plotted in Fig. 1 as a function of distance. The values for $c$ used in the model were $10^{-2}$ to simulate poor isolation between fields and $10^{-7}$ for good isolation. Intermediate values were also used. According to (3) and the estimated parameters, assuming the most favourable conditions for spore dispersal, the two extreme values for $c$ correspond with distances of $200 \mathrm{~m}$ and $800 \mathrm{~m}$ between two $100 \mathrm{~m} \times 100 \mathrm{~m}$ fields, respectively (Fig. 1).

The value for $f$ is a measure for the level of background infection as determined by the intensity of leek growing and presence of leek rust in the region. These factors cannot be manipulated by individual farmers. The values for $f$ used in the simulations are $10^{-7}$ for low and $10^{-5}$ for high background infection levels, representing 0.01 and 1 infection per day, respectively, for a field with 100.000 plants (approx. one hectare). The factor $s(t)_{i}$ equals 0.05 when field $i$ is protected and 1 otherwise, thus simulating an efficacy of the fungicide of $95 \% . X_{0}$ represents the disease level in the planting material and was assumed to be zero or 0.1 pustule per plant, to simulate healthy and infected planting material, respectively.

\section{Model scenarios}

The model (1) is used to calculate the yearly total number of sprays during ten years for ten scenarios. Every scenario is defined by a combination of the three cropping conditions that are influenced by strategic preventive measures: level of background infection $(f)$, 


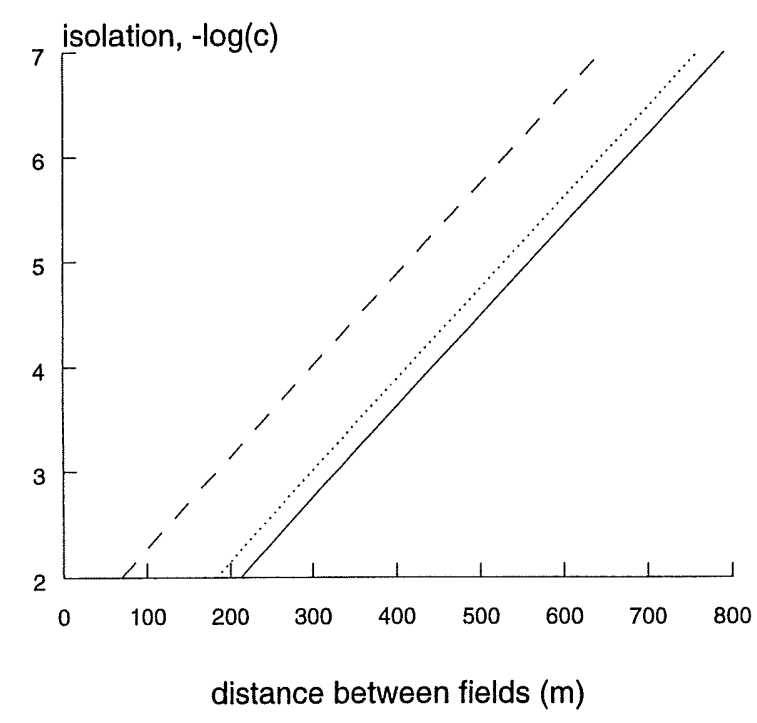

Fig. 1. The relation between isolation $(-\log (c))$ and the distance between the border of equally sized fields as calculated with (3), $a$ $=4.9 * 10^{-5}, b=0.02$ and planting distance $0.5 \mathrm{~m} \times 0.2 \mathrm{~m}$ for fields measuring $10 \mathrm{~m} \times 10 \mathrm{~m}$ (dashed line), $50 \mathrm{~m} \times 50 \mathrm{~m}$ (dotted line) and fields measuring $100 \mathrm{~m} \times 100 \mathrm{~m}$ (solid line).

isolation between fields $(c)$ and cropping pattern. The three cropping patterns used are given in Fig. 2. Pattern A has the maximum possible overlap between successive crops. Pattern B has overlap only between the autumn and winter crops. Pattern $C$ differs from pattern $\mathrm{B}$ in that the harvests of the winter and summer crops are delayed by one week. Thus two crops overlap one week with subsequent crops. Cropping patterns A and $\mathrm{C}$ are combined with two levels of background infection level $(f)$ and isolation between fields $(c)$. Cropping pattern $\mathrm{B}$ is combined with two levels of $f$ and only one value of $c$, because the lack of overlap between crops makes the model results insensitive to the latter parameter. The resulting ten scenarios are given in Table 2. For every scenario, calculations are done for healthy and diseased planting material $\left(X_{0}\right)$ and normal and slow rust increase $(r)$, factors that are influenced by the tactical preventive measures. The calculations were started on 1 April in the first year. The number of pustules per plant in the standing winter crop is given a range of arbitrary values to test the sensitivity of the model to this initial disease level.

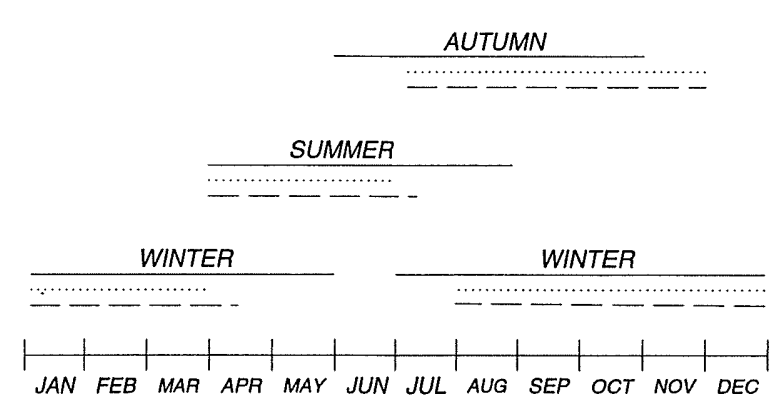

Fig. 2. The cropping patterns used for the simulations; solid line: pattern $\mathrm{A}$, the maximal possible overlap between the successive crops; dotted line: pattern B, only overlap between the autumn crop and the winter crop; dashed line: pattern $C$, differs from pattern $B$, in that the harvests of winter and summer crops are delayed by one week.

\section{Results}

For all scenarios, a stable equilibrium for the annual number of sprays occurs before the fifth year and was independent of the number of pustules per plant in the standing winter crop at the beginning of the simulations. The simulated total number of sprays in the fifth year is given in Table 2 for the ten scenarios. With scenarios 1 and 2, i.e. when the cropping pattern had ample overlap between successive crops (cropping pattern A) and poor isolation between the fields in the farm $\left(c=10^{-2}\right)$, a large number of sprays was simulated independently of the influx of spores from outside the farm $(f)$. The model results show that a farmer growing leeks under these conditions is committed to heavy use of fungicides. The application of supervised control, care for healthy planting material or even the use of a still hypothetical partially resistant cultivar does not lead to the expected reduction in fungicide use as compared to the 30 sprays used with calendar spraying. With scenarios 3 and 4, i.e. cropping pattern $A$ and good isolation between the crops $\left(\mathrm{c}=10^{-7}\right)$, the simulated number of sprays was greatly reduced, with the greatest reduction simulated for scenario 4 , i.e. a low influx of spores $\left(f=10^{-7}\right)$. The use of a partially resistant cultivar or cropping practices which restrain the disease reduced the simulated number of sprays to zero for both scenarios 3 and 4 . The simulated reduction in the number of sprays was fully dependent on the use of healthy planting material; this is also illustrated in Fig. 3 for intermediate levels of isolation.

The use of a cropping pattern with overlap only between the autumn and winter crops will reduce the need for effective chemical control, as suggested by 
Table 2. Simulated total number of sprays per year in the fifth year for the ten scenarios

\begin{tabular}{|c|c|c|c|c|c|c|c|}
\hline \multirow[t]{4}{*}{ Senario } & \multicolumn{3}{|c|}{ Strategic preventive measures } & \multirow{2}{*}{\multicolumn{4}{|c|}{$\begin{array}{l}\text { Tactical preventive measures } \\
\text { Disease increase: } r \\
\text { Planting material: } \mathrm{H}, \mathrm{D}^{3}\end{array}$}} \\
\hline & \multirow[t]{3}{*}{$\begin{array}{l}\text { Cropping } \\
\text { pat. }\end{array}$} & \multirow[t]{3}{*}{ Isolation ${ }^{1}$} & \multirow[t]{3}{*}{$\begin{array}{l}\text { Background } \\
\text { infect. }^{2}\end{array}$} & & & & \\
\hline & & & & $r=$ & & $r=$ & \\
\hline & & & & $\mathrm{H}$ & $\mathrm{D}$ & $\mathrm{H}$ & $\mathrm{D}$ \\
\hline 1 & A & poor & high & 29 & 29 & 25 & 26 \\
\hline 2 & A & poor & low & 29 & 29 & 25 & 26 \\
\hline 3 & A & good & high & 13 & 27 & 0 & 23 \\
\hline 4 & A & good & low & 4 & 27 & 0 & 23 \\
\hline 5 & B & poor & high & 1 & 14 & 0 & 11 \\
\hline 6 & $\mathrm{~B}$ & poor & low & 0 & 14 & 0 & 11 \\
\hline 7 & $\mathrm{C}$ & poor & high & 15 & 17 & 8 & 12 \\
\hline 8 & $\mathrm{C}$ & poor & low & 15 & 17 & 4 & 12 \\
\hline 9 & $\mathrm{C}$ & good & high & 1 & 15 & 0 & 11 \\
\hline 10 & $\mathrm{C}$ & good & low & 0 & 15 & 0 & 11 \\
\hline
\end{tabular}

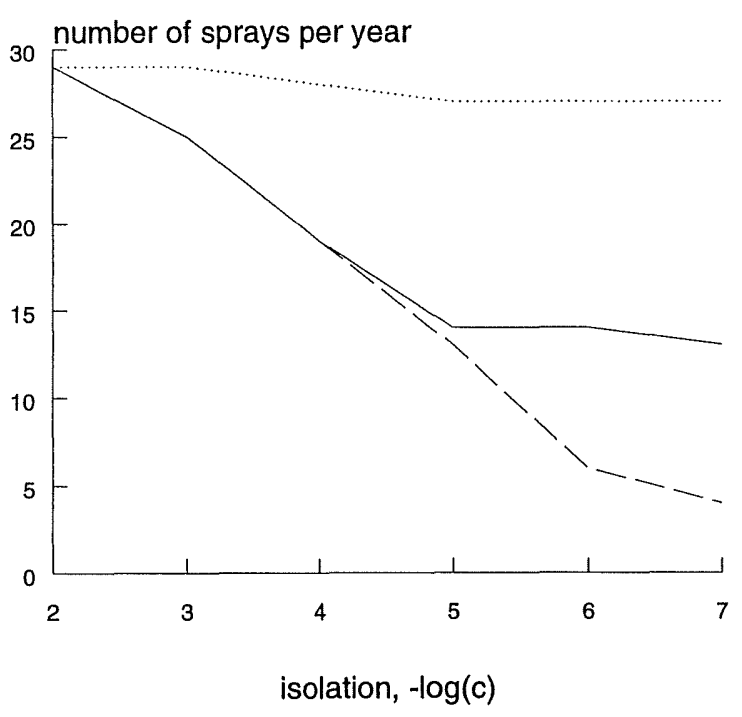

Fig. 3. The reduction in the simulated number of sprays for cropping pattern $\mathrm{A}$ as a function of the isolation $(-\log (c))$ between fields; dotted line: diseased planting material and high or low background infection level; solid line: healthy planting material and high background infection level; dashed line: healthy planting material and low background infection level.

the results of scenarios 5 and 6. Part of the reduction in the simulated number of sprays can be explained by the shorter growing period of the crops, which resulted in a reduced number of sprays to 18 under calendar application. The considerable reduction in the sim- ulated number of sprays relative to calendar spraying was absent when infected planting material was used or when a small overlap of one week was allowed between successive crops (cropping pattern $\mathrm{C}$ ) and the isolation between the crops was poor $\left(c=10^{-2}\right)$ (scenarios 7 and 8). With scenarios 9 and 10, i.e. a good isolation between the fields $\left(c=10^{-7}\right)$, the number of sprays was less sensitive to a short overlap between successive crops.

\section{Discussion}

The loss of quality associated with a light infestation of leek rust may cause severe economic loss to the grower, due to the high value of the crop and the strict grading system. Therefore, regular chemical control of the disease has to start as soon as the disease has entered the crop and there is therefore little practical use for a quantitative control threshold, as was also found by Nyrop et al. [1989] for chemical control against leek moth (Acrolepiopsis assectella Z.). Applying fungicides to a leek crop in the absence of the disease is undesirable, both from environmental and economic points of view. A sampling procedure for detection of leek rust has already been developed [de Jong, 1995]. Although the procedure of delaying chemical control until detection of the disease does not use a quantitative control threshold, it can still be regarded as a form of super- 
vised control (sensu Theunissen [1984]). In the intensive leek growing areas in the south of the Netherlands, it is common practice to grow poorly isolated and overlapping crops on the same farm. The simulation results obtained suggest that under these cropping conditions, supervised control is not effective in reducing the number of sprays against leek rust. An alternative strategy of supervised control is to protect all crops during the growth of one or more visibly infected crops, instead of spraying the visibly infected crops only; this was evaluated in preliminary calculations but did not reduce the simulated number of sprayings under these conditions, because the chemical protection of visibly uninfected crops itself required extra fungicide applications.

The use of healthy planting material was a prerequisite for reduction in fungicide sprays by any other preventive measure. Most leek growers in the Netherlands order their planting material from specialized nurseries about four months before planting but this may be infected in the nursery and should be inspected before acceptance. Refusal of infected planting material will lead to the additional costs of obtaining alternative planting material without a timely order, and this may compel the farmer to accept inferior material with latent infections. The simulation results point to the importance of good nursery hygiene. With healthy planting material, the simulated number of sprays was greatly reduced by increased isolation between the fields in one farm. The simulation results are supported by the findings of Weisz et al. [1994], who found a reduction in infestation by colorado potato beetle (Leptinotarsa decemlineata Say) and early blight (Alternaria solani Sor.) and a subsequent decrease in the need for chemical control due to increased isolation of potato fields. Isolation between fields can be obtained by increasing the distance between fields and by growing border rows with a buffer crop, e.g. maize. For small farms, increasing the distance between fields will require purchase of land or exchange of land with a non-leek farmer. Little information is available in the literature on the quantitative effect of a buffer crop on spore dispersal. Boudreau and Mundt [1992] found that the addition of a single maize row between source plants and trap plants did not alter the dispersal gradient of bean rust (Uromyces appendiculatus (Pers.) Unger). Change to a cropping pattern with no overlap in time between successive crops also reduced the simulated number of sprays, provided that healthy planting material was used. A serious drawback, however, is the shorter growing period that will inevitably result in a lower yield.
The results from this study suggest further research along two lines. Firstly, a more comprehensive model needs to be developed, containing variable growth rates and latent periods depending on weather conditions and growth stages of the crop, and a more realistic description of the dispersal of spores between fields and the influx of spores from outside the farm. Substantial experimental work will be needed to quantify these relations. Secondly, the results of the model should be tested against field observations. The scale of the problem requires large experiments, as performed by Weisz et al. [1994]. To avoid such large experiments, the field observations can be collected in a survey of leek growers applying supervised control which should cover a sufficient number of growers representing a range in cropping patterns, farm size, etc. over several years to rule out exceptional weather conditions. The efforts in further research will be rewarded by an increased insight into the possibilities for reducing fungicide use by means of preventive measures; a similar study may be useful for other pathosystems in which supervised control has not resulted in the expected reduction in pesticide use.

\section{Acknowledgements}

Thanks are due to dr.ir. J. A. P. Heesterbeek for checking the mathematical equations and the many critical readers of earlier drafts.

\section{References}

Albert J and Smolka SE (1994) Die Erreger des Rostes an AlliumArten und Beobachtungen zur physiologischen Spezialisierung von Puccinia allii an Porree. Mitt ad Biol Bundesanst 301: 138

Aylor DE (1987) Deposition gradients of urediniospores of Puccinia recondita near a source. Phytopathology 77: 1442-1448

Boudreau MA and Mundt CC (1992) Mechanisms of alteration in bean rust epidemiology due to intercropping with maize. Phytopathology 82: 1051-1060

Conway GR (ed) (1984) Pest and Pathogen Control: Strategic, Tactical and Policy Models. Wiley - International Institute for Applied Systems Analysis, 488 p

Fitt BDL, Gregory PH, Todd AD, McCartney HA and MacDonald OC (1987) Spore dispersal and plant disease gradients; a comparison between two empirical models. J Phytopathology 118: 227-242

Jennings DM, Ford-Lloyd BV and Butler GM (1990a) Rust infections of some Allium species: an assessment of germplasm for utilizable rust resistance. Euphytica 49: 99-109

Jennings DM, Ford-Lloyd BV and Butler GM (1990b) Effect of plant age, leaf position and leaf segment on infection of leek rust, Puccinia allii. Plant pathology 39: 591-597 
de Jong PD (1994) Growth of leek rust epidemics in time in three cultivars during the early stage of the epidemic. Eur J Pl Path 101: 139-148

de Jong PD (1995) Sampling for detection, leek rust as an example. Int J Pest Management (in press)

Kiyosawa S and Shiyomi M (1972) A theoretical evaluation of the effect of mixing resistant variety with susceptible variety for controlling plant disease. Ann Phytopath Soc Japan 38: 41-51

von Meyer W and Kessler H (1990) Ansätze für einen integrierten Pflanzenschutz bei Porree. Gesunde Pflanzen 42/9: 295-300

Niks RE and Butler GM (1993) Evaluation of morphology of infection structures in distinguishing between different Allium rust fungi. Neth J Pl Path 99 Supplement 3: 139-149

Nyrop JP, Shelton AM and Theunissen J (1989) Value of a control decision rule for leek moth infestations in leek. Entomol exp appl 53: 167-176
Smith BM and Crowther TC (1992) Field assessment of the reaction of leek cultivars to leek rust. Tests of Agrochemicals and Cultivars 13, Ann appl Biol 120(Supplement): 104-105

Theunissen J (1984) Supervised pest control in cabbage crops: theory and practice. Mitteilungen aus der Biologischen Bundesanstalt für Land-und Forstwirtschaft 218: 76-84

Uma NU and Taylor GS (1991) Reaction of leek cultivars to infection by Puccinia allii. Plant Pathology 40: 221-225

Weisz R, Smilowitz Z and Christ B (1994) Distance, rotation and border crops affect colorado potato beetle (Coleoptora: Chrysomelidae) colonization and population density and early blight (Alternaria solani) severity in rotated potato fields. Journal of Economic Entomology 87: 723-729 